\title{
Protective activity ethanol extract of the fruits of Illicium verum against atherogenesis in apolipoprotein E knockout mice
}

\author{
Sun Haeng Park, Yoon-Young Sung, Kyoung Jin Nho and Ho Kyoung Kim*
}

\begin{abstract}
Background: Illicium verum Hook. fil. Illiciaceae (Illicium v.) has been traditionally used in herbal medicine for treating many inflammatory diseases, including skin inflammation and rheumatism. We investigated its use as a preventive agent against inflammatory and vascular diseases in a murine model of atherosclerosis using apolipoprotein E-knockout $\left(A p o E^{-/-}\right)$mice fed on a high-fat diet (HFD).
\end{abstract}

Methods: We investigated the effect of Illicium v. on cytotoxicity, NF-kB activity, and adhesion molecule expression in TNF-a - stimulated HASMCs (Human Aortic smooth muscle cells). ApoE ${ }^{-}{ }^{-}$mice, fed a HFD and treated daily for 12 weeks by oral administration of either Illicium v. (100 or 200 mg/kg) or atorvastatin (10 mg/kg), were evaluated for atherosclerotic lesions and inflammatory responses by performing Oil red $O$ and iNOS staining, respectively.

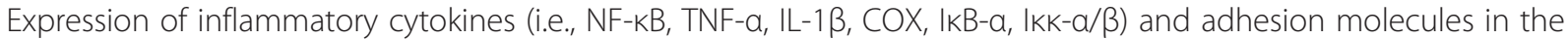
aorta were measured by western blot analysis.

Results: In TNF-a-stimulated HASMCs, Illicium v. treatment decreased NF-KB transcriptional activity, and NF-KB protein levels were reduced in a dose-dependent manner over a range of $10-100 \mu \mathrm{g} / \mathrm{mL}$ Illicium v. Also, Illicium v. attenuated the expression of adhesion molecules that are responsible for inflammation in these cells. In animal experiments, treatment with Illicium v. or atorvastatin counteracted the characteristic changes in body weight, blood pressure, and lipid levels seen in HFD-fed $A p o E^{-1-}$ mice. In addition, Illicium v. treatment reduced aortic atherosclerotic plaque lesions and the immunoreactivity of iNOS activation. The aortic expression of inflammatory adhesion molecules

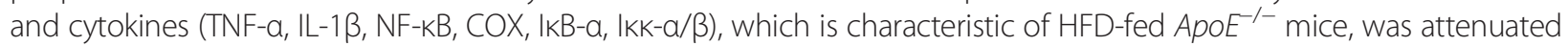
by 12 -week treatment with daily oral administration of Illicium $v$. or atorvastatin, and the most potent effect was seen with the herbal tincture.

Conclusions: The beneficial effects of Illicium v. are consistent with a significant decrease in the iNOS-mediated inflammatory response, resulting in reduction of inflammation-associated gene expression. Treatment with Illicium $\mathrm{v}$. may be the basis of a novel therapeutic strategy for hyperlipidemia-atherosclerosis.

Keywords: Atherosclerosis, ApoE-knockout mice, Inflammation, Hypercholesterolemia, Illicium verum

\section{Background}

Hyperlipidemia plays an important role in the pathogenesis of atherosclerosis in prehypertension [13]. Many studies have demonstrated that systemic inflammation and the immune system play a central role in atherogenesis. Strong dependence of the atherosclerotic process on both a state of continuous low-grade inflammation

\footnotetext{
* Correspondence: hkkim@kiom.re.kr

Mibyeong Research Center, Korea Institute of Oriental Medicine (KIOM), 1672 Yuseong-daero, Yuseong-gu, Daejeon 305-811, South Korea
}

and presence of lipid abnormalities gave impetus in the field to examine the association between hyperlipidemia and inflammatory status [26]. Recent studies in hyperlipidemic mice have demonstrated that anti-inflammatory compounds prevent development of atherosclerosis without altering blood lipid profiles [2, 12, 22]. Furthermore, anti-inflammatory drugs there are other agents that can reduce the occurrence of atherosclerosis without altering blood lipid profiles in this murine model, indicating that anti-inflammatory compounds may be used 
as therapeutic drugs for the treatment of hyperlipidemiaatherosclerosis [16].

Monocytes and macrophages infiltrate areas of atherosclerotic lesions and increase expression of adhesion molecules and inflammation-related genes, such as ICAM, VCAM, NF- $\mathrm{kB}$, and iNOS, that are important for development and progression of atherosclerosis $[3,12]$. In particular, large amount of locally released NO has been linked to generation of harmful oxidative products, such as peroxynitrite, that have been implicated in iNOS-mediated development of atherosclerosis [31]. The hypothesis that iNOS plays a causative role in the progression of atherosclerosis is supported by the observation that atherosclerotic lesions are diminished in $i N O S / A p o E$ double-knockout mice relative to $A p o E^{-/-}$mice [15]. Furthermore, iNOS expression is activated by NF- $\mathrm{kB}$, which is responsive to inflammation and oxidative stress [23]. Therefore, understanding mechanisms of iNOS regulation may provide new targets for the treatment of hyperlipidemia-atherosclerosis.

Illicium verum Hook. fil. Illiciaceae (Illicium v.), is widely used for culinary and medicinal purposes, and it is taken as a natural remedy by many patients. The fruit of the plant has been used in traditional medicine for treatment of stomach aches, vomiting, rheumatic pain, insomnia, and skin inflammation [11, 18, 27, 30], and it has been reported to have beneficial anti-inflammatory effects. These effects have been shown with ethanolic Illicium $v$, extracts to be mediated by suppressing the expression of TNF- $\alpha$ - and IFN- $\gamma$-stimulated chemokine and cytokine expression in vitro and in vivo [20, 27, 28]. Illicium $v$. contains ten main chemical entities (i.e., linoleic acid, palmitic acid, trans-anethole, anisaldehyde, estragole, limonens, $(Z)$-anethole, pinene, $\beta$-phellandraene, and $\alpha$ terpineol) that have various anti-inflammatory pharmacological effects [7, 14, 25, 28].

Given the known inflammatory component in atherosclerosis, it is perhaps surprising that Illicium $v$. has not yet been tested as a potential treatment for atherosclerosis or hyperlipidemia in an animal model. It is reasonable to hypothesize that Illicium $v$. might be efficacious because of its demonstrated anti-inflammatory action in other settings. We hypothesized that Illicium $v$. would be active as an anti-inflammatory agent in $A p o E^{-/-}$mice and would inhibit atherosclerosis in these animals when they are fed a high-fat diet (HFD), which is an accepted mechanism-based animal model for the disease. A number of parameters were investigated in vivo, such as body weight, blood lipid levels, and blood pressure, during HFD-induced atherosclerosis to evaluate activity of Illicium $v$. Effects of the extract on expression of atherosclerosis-related adhesion molecules and anti-inflammatory signaling in human smooth muscle cells (HASMCs), as well as in $A p o E^{-/-}$mouse aortas, were assessed.

\section{Methods}

\section{Cell culture}

Cryopreserved HASMC were purchased from ScienCell Research Laboratory (San Diego, CA, USA). Cells were cultured as monolayers in smooth muscle cell medium (ScienCell) containing essential and nonessential amino acids, vitamins, organic and inorganic compounds, hormones, growth factors, trace minerals, and $2 \%(v / v)$ fetal bovine serum at $37{ }^{\circ} \mathrm{C}$ in a humidified $5 \% \mathrm{CO}_{2}$ atmosphere. Cells from passages 2 to 6 were used in this study.

\section{Experimental animals and diet}

Male $A p o E^{-1-}$ mice in a C57BL/6 N background (6 weeks of age) were from the Jackson Laboratory (Bar Harbor, ME, USA). They were housed under diurnal lighting conditions and allowed food and tap water ad libitum. All experimental protocols involving use of animals were conducted in accordance with the National Institutes of Health guidelines and approved by the Committee on Animal Care of KIOM.

The mice fed on a High Fat diet (45\% of total calories from fat; $0.15 \%$ cholesterol; Research Diet, New Brunswick, NJ, USA) were divided into five groups: control (chow diet, $n=8$ ), HFD (High Fat Diet, $n=8$ ), Illicium v. $100 \mathrm{mg} / \mathrm{kg}$ treatment (HFD with Illicium $v$. $100 \mathrm{mg} / \mathrm{kg}, n=8$ ), Illicium v. $200 \mathrm{mg} / \mathrm{kg}$ (HFD with Illicium v. $200 \mathrm{mg} / \mathrm{kg}, n=8$ ), and atorvastatin $10 \mathrm{mg} / \mathrm{kg}$ (HFD with atorvastatin $10 \mathrm{mg} / \mathrm{kg}, n=8$ ). Daily treatments were given orally over a 12 -week period, during which experimental animals were fed a HFD.

\section{Preparation of Illicium verum extract}

Illicium v. material was purchased from Omniherb Co. (Yeongcheon, South Korea) and was authenticated based on its microscopic and macroscopic characteristics by the Classification and Identification Committee of the KIOM. A voucher specimen has been deposited at the herbarium of the Basic Herbal Medicine Research Group at KIOM. Dried fruit (300 g) was extracted twice with $70 \%(v / v)$ ethanol (with a 2-h reflux). The extract was concentrated under reduced pressure at $40{ }^{\circ} \mathrm{C}$ with a rotary evaporator. The decoction was filtered, lyophilized, and stored at $4{ }^{\circ} \mathrm{C}$ until use (Sung et al. [27]). The yield of the dried extract from the starting crude materials was approximately $15.73 \%(w / w)$. The lyophilized powder was dissolved in 0.05-0.1\% dimethyl sulfoxide and then filtered through a $0.22 \mu \mathrm{m}$ syringe filter to create a stock solution.

\section{Cell viability}

A standard assay based on the tetrazole (3-(4,5-dimethylthiazol-2-yl)-2,5-diphenyltetrazolium bromide (MTT) was used to assess cell viability. Briefly, HASMCs were 
seeded in 96-well microtiter plates at a density of $1 \times 10^{5}$ cells/well. They were treated with various concentrations of Illicium v. (10, 50, or $100 \mu \mathrm{g} / \mathrm{mL})$ for $24 \mathrm{~h}$. Subsequently, $100 \mu \mathrm{L}$ of $5 \mathrm{mg} \mathrm{MTT} / \mathrm{mL}$ in PBS was added to each well, and the plates were incubated at $37{ }^{\circ} \mathrm{C}$ for $4 \mathrm{~h}$ before adding $200 \mu \mathrm{L}$ DMSO to dissolve formazan crystals. Absorbance was measured at $540 \mathrm{~nm}$ by spectrophotometry.

\section{$N F-K B$ activity assay}

Activity of NF- $\mathrm{kB}$ was measured by luciferase reporter assays in HASMC. Cells in 12-well plates were cotransfected with a firefly luciferase gene tagged with renilla luciferase and pGL4.32-NF- $\mathrm{kB}$, using the FuGENE HD reagent (Invitrogen; Carlsbad, CA, USA). Medium was replaced with fresh medium after $6 \mathrm{~h}$. At $24 \mathrm{~h}$ post transfection, cells were stimulated with TNF- $\alpha$ (10 ng/ $\mathrm{mL}, \mathrm{R} \& \mathrm{D}$ Systems Inc.; St. Louis, Mo, USA) in the presence of 10, 50, or $100 \mu \mathrm{g}$ Illicium $v . . / \mathrm{mL}$. Luciferase activity was assayed $24 \mathrm{~h}$ later using a dual-luciferase reporter assay system (Promega; Madison, Wl, USA).

\section{Measurement of serum markers}

Blood was collected from the aorta under light anesthesia and stored on ice for $30 \mathrm{~min}$ before centrifugation at $13,000 \mathrm{rpm}$ at $4{ }^{\circ} \mathrm{C}$ for $10 \mathrm{~min}$, and the serum was separated and kept at $-80^{\circ} \mathrm{C}$ until it was thawed for the assay. Serum levels of total cholesterol, high-density lipoprotein (HDL), low-density lipoprotein (LDL), triglycerides, glucose, alanine aminotransferase (ALT), aspartate aminotransferase (AST), and creatinine were measured with an automatic analyzer.

\section{Blood pressure measurement}

Blood pressure was monitored using a noninvasive tailcuff CODA ${ }^{\mathrm{TM}}$ system (Kent Scientific; Torrington, CT, USA) as previously described [17].

\section{Histopathology}

Mice were deeply anesthetized with sodium thiopental and subsequently the tissue was removed and then washed with cold PBS and followed fixation with $4 \%(w / v)$ paraformaldehyde. The aorta of each mouse was then removed and further fixed in the same solution for $24 \mathrm{~h}$ at $4{ }^{\circ} \mathrm{C}$. Fixed aortas were frozen and stored at $-80^{\circ} \mathrm{C}$. Sections of $10-\mu \mathrm{m}$ thickness were sliced from frozen tissue and then immunostained with antibodies against iNOS(Thermo Scientific; Rockford, IL USA). After additional incubation with secondary antibody, sections were reacted with 3amino-9-ethylcarbazole chromogen (Vector Laboratories; Burlingame, CA, USA). Reactions with 3,3' diaminobenzidine substrate (Vector Laboratories) were performed for color development, and the stained sections were then analyzed by light microscopy.

\section{Western blot analysis}

Proteins were isolated from aortic tissue according to standard techniques [4], separated by $10 \%$ sodium dodecyl sulfate-polyacrylamide gel electrophoresis and then transferred onto nitrocellulose membranes (Amersham Biosciences; Piscataway, NJ, USA). Blots were probed with primary antibodies directed against VCAM-1 or NF-кB (Santa Cruz Biotechnology; San Cruz, CA, USA), or against ICAM-1, E-selectin, TNF- $\alpha$, IL-1 $\beta$, COX, IкB$\alpha$, or Iкк- $\alpha / \beta$, iNOS (Cell Signaling Technology; Beverly, MA, USA). This was followed by incubation with secondary antibody conjugated to horseradish peroxidase (Cell Signaling). Bound secondary antibody was detected by chemiluminescence generated by peroxidase reaction, measured with an ImageQuant LAS 4000 apparatus (GE Healthcare Life Sciences; Buckinghamshire, UK). Membranes were reprobed with an anti- $\beta$-actin antibody (Sigma-Aldrich Chemical Co.; St. Louis, MO, USA) as internal sample control.

\section{Data analysis}

The data are expressed as mean values \pm SEM. Statistical comparisons were performed using analysis of variance for repeated measures, followed by Sigmastat statistical program Version 11.2 (Systat Software, San Jose, CA, USA). Data were analyzed statistically using two-way ANOVA via Tukey's post hoc comparison when comparing more than two groups. A value of $P<0.05$ was considered to be statistically significant.

\section{Results}

Illicium v. effects on TNF-a-stimulated HASMCs

Cytotoxic effect of Illicium $v$. was assessed at different concentrations $(0,10,50$, or $100 \mu \mathrm{g} / \mathrm{mL})$ by MTT assay in HASMCs. At concentrations in this range, Illicium v. did not cause any apparent cytotoxicity (Fig. 1a). We evaluated the ability of Illicium $v$. to decrease pro-inflammatory NF- $\kappa B$ activity in TNF- $\alpha$-stimulated HASMCs. The TNF$\alpha$-stimulated NF- $\mathrm{kB}$ transcription activity $(22.03 \pm 0.25$ vs. control group) was markedly reversed by Illicium $v$. in a dose-dependent manner (Fig. 1b). The activity was decreased by 50 and $100 \mu \mathrm{g} / \mathrm{mL}$ Illicium $v$. decreased to $10.39 \pm 0.06$ and $9.17 \pm 0.07$, respectively $(P<0.01, P<0.05$ vs. TNF- $\alpha$-stimulated group). Furthermore, NF- $\mathrm{kB}$ protein level was decreased by Illicium $\nu$. in TNF- $\alpha$-stimulated HASMCs (Fig. 1c). Western blot analysis revealed that adhesion molecule (ICAM, VCAM, and E-selectin) expression was induced in the TNF- $\alpha$-stimulated group. Illicium $v$. significantly antagonized TNF- $\alpha$-induced ICAM, VCAM, and E-selectin expression (Fig. 1d). Transcriptional activity of many of these inflammatory cytokines and adhesion molecules is controlled by NF-kB. These results show that Illicium $v$. suppresses production of inflammatory mediators in vitro. 


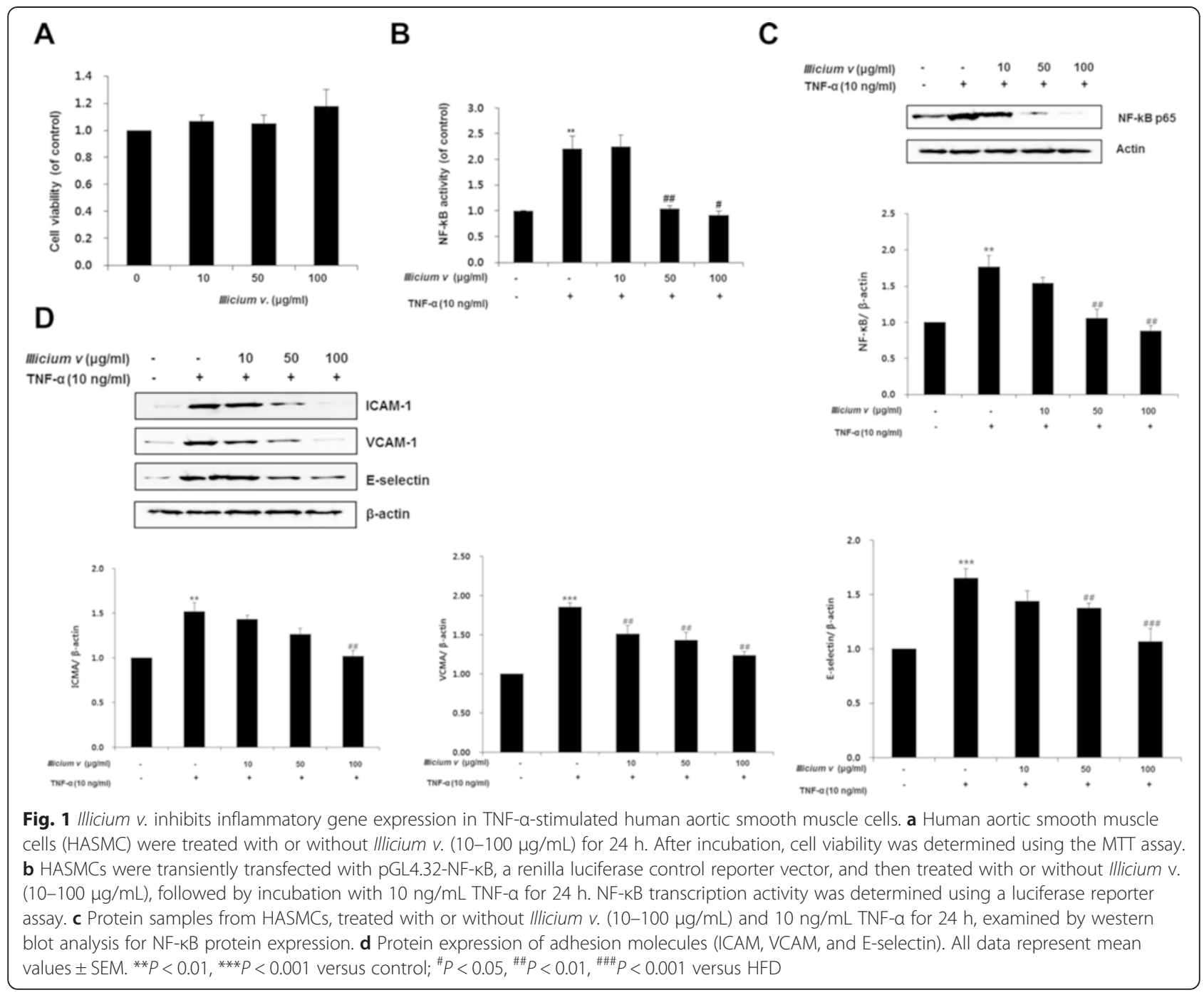

Body weight and blood pressure in treated and untreated HFD-fed ApoE ${ }^{-/-}$mice

Body weights of $A p o E^{-/-}$mice fed on a HFD for 12 week were higher than those in normal diet-fed mice (control) $(28.2 \pm 0.60$ vs. $40.0 \pm 2.10 \mathrm{~g}, P<0.001)$. However, the Illicium v. 100 and $200 \mathrm{mg} / \mathrm{kg}$ group mean body weights were significantly lower than those of mice in the HFD group $(33.5 \pm 1.40$ and $29.3 \pm 0.78$ g vs. HFD group, $P<$ 0.01 and $P<0.001$, respectively). This was similar to the effect of atorvastatin $(33.2 \pm 1.85$ vs. HFD group, $P<$ 0.05; see Table 1 and Fig. 2a). Next, we confirmed that Illicium $v$. reduced blood pressure. During the course of

Table 1 Physiological parameters

\begin{tabular}{lllll}
\hline & & Blood pressure $(\mathrm{mm} \mathrm{Hg})$ & & \\
& Body weight $(\mathrm{g})$ & Mean pressure & Diastolic & Systolic \\
\hline Con & $28.2 \pm 0.60$ & $86 \pm 5.559$ & $77 \pm 6.19$ & $105 \pm 3.51$ \\
HFD & $40.0 \pm 2.10^{* * *}$ & $111 \pm 8.80^{*}$ & $109 \pm 8.41^{* *}$ & $135 \pm 6.52^{* *}$ \\
Illicium v., $100 \mathrm{mg} / \mathrm{kg}$ & $33.5 \pm 1.40^{\#}$ & $87 \pm 7.13^{\#}$ & $79 \pm 8.42^{\# \#}$ & $104 \pm 4.91^{\# \#}$ \\
Illicium v., $200 \mathrm{mg} / \mathrm{kg}$ & $29.3 \pm 0.78^{\# \# \#}$ & $66 \pm 2.16^{\# \#}$ & $59 \pm 2.04^{\# \#}$ & $82 \pm 2.83^{\# \# \#}$ \\
Atorvastatin & $33.2 \pm 1.85^{\#}$ & $93 \pm 2.66^{\#}$ & $83 \pm 1.94^{\# \#}$ & $115 \pm 4.84^{\#}$ \\
\hline
\end{tabular}

Abbreviations: Con, control; HFD, high-fat diet

All data represent mean values \pm SEM. $(n=8)$

${ }^{*} P<0.05,{ }^{* *} P<0.01$ and ${ }^{* * *} P<0.001$, versus chow diet fed $A p o E^{-1-}$ mice (control)

${ }^{\#} P<0.05,{ }^{\# \#} P<0.01$ and ${ }^{\# \# \#} P<0.001$, versus HFD-fed $A p o E^{-1-}$ mice (HFD) 


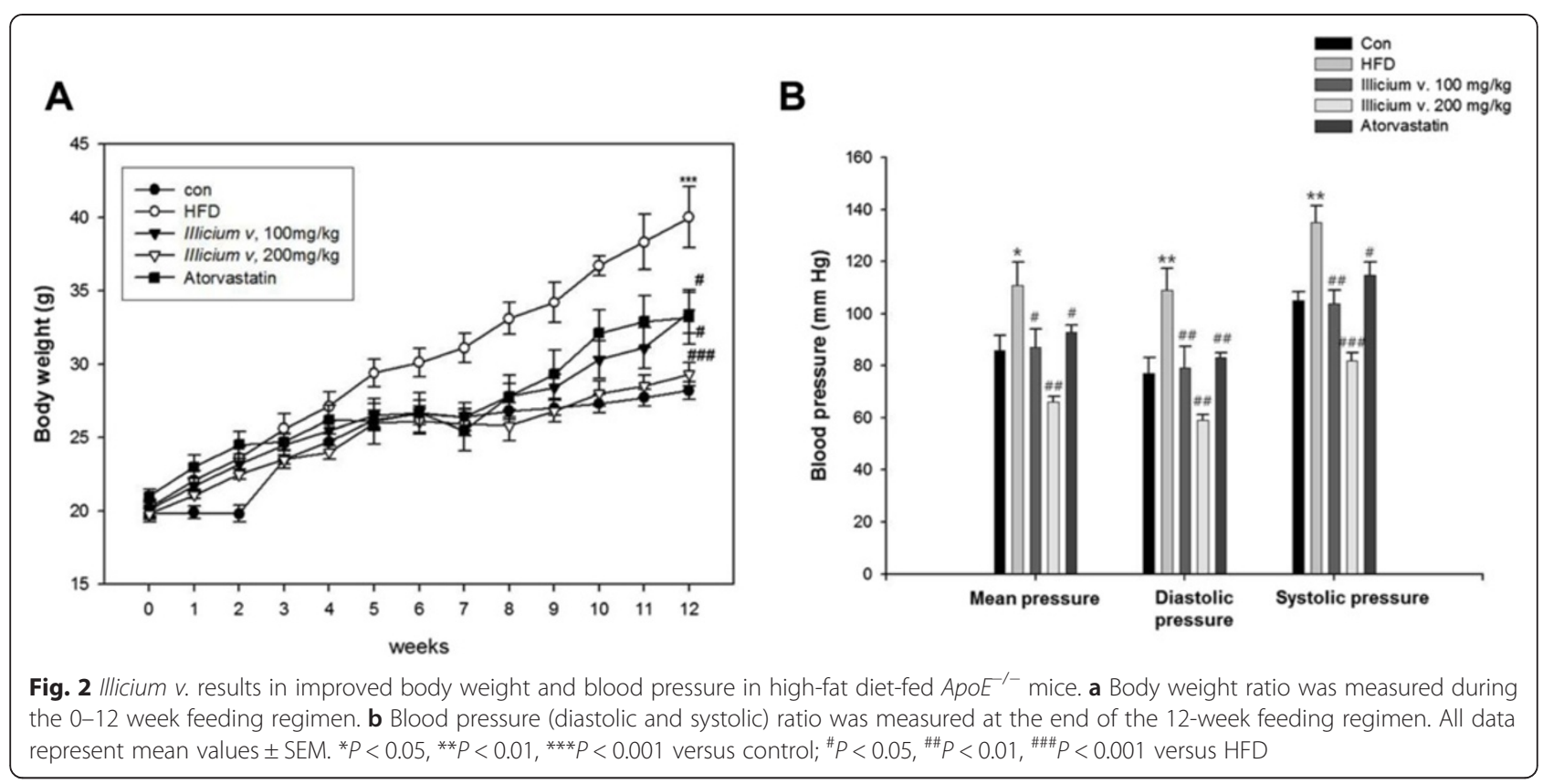

the experiment, blood pressure in the HFD group was significantly higher than that in the control group (86 \pm 5.59 vs. $111 \pm 8.80 \mathrm{mmHg}, P<0.05)$. In contrast, the blood pressure was significantly lower in the groups treated with either Illicium v. at $100 \mathrm{mg} / \mathrm{kg}(87 \pm 7.13 \mathrm{mmHg}, P<0.05)$ or at $200 \mathrm{mg} / \mathrm{kg}(66 \pm 2.16 \mathrm{mmHg}, P<0.01)$ or in the atorvastatin group $(93 \pm 2.66 \mathrm{mmHg}, P<0.05)$ than HFD group. Moreover, diastolic and systolic blood pressure levels were significantly reduced in the Illicium $v$. and atorvastatin treatment groups (Table 1 and Fig. 2b).

\section{Blood lipid levels}

Illicium v.- or atorvastatin-treated HFD-fed $A p o E^{-/-}$ mice showed significantly decreased total and LDL cholesterol levels $(P<0.05$ and $P<0.01$ vs. HFD group;
Table 2). Moreover, glucose levels were decreased in Illicium v. $50 \mathrm{mg} / \mathrm{kg}$ and $100 \mathrm{mg} / \mathrm{kg}$ groups $(245.67 \pm 14.54$ and $215.33 \pm 10.23$ vs. HFD group, $P<0.01$ and $P<$ 0.001 , respectively). Potential toxicity did not differ among mice treated with Illicium $v$. or atorvastatin, at inhibitory concentrations of both agents.

\section{Illicium $v$. attenuates formation of atherosclerotic plaque lesions}

We investigated whether Illicium $v$. exerts an antiatherosclerotic effect in HFD-fed $A p o E^{-/-}$mice by quantifying atherosclerotic plaque lesional areas. Consecutive cross sections of aortas stained with Oil red $\mathrm{O}$ revealed induction of plaque formation. The mice that were fed a HFD for 12 weeks exhibited significantly increased aortic

Table 2 Lipid parameters

\begin{tabular}{|c|c|c|c|c|c|}
\hline & \multicolumn{5}{|c|}{ Illicium verum } \\
\hline & Con & HFD & $100 \mathrm{mg} / \mathrm{kg}$ & $200 \mathrm{mg} / \mathrm{kg}$ & Atorvastatin \\
\hline T-chole (mg/dL) & $502.40 \pm 22.79$ & $1112.00 \pm 120.77^{* * * *}$ & $635.50 \pm 106.12^{\#}$ & $608.00 \pm 49.50^{\# \#}$ & $655.25 \pm 60.80^{\#}$ \\
\hline $\mathrm{LDL}(\mathrm{mg} / \mathrm{dL})$ & $79.60 \pm 7.86$ & $244.00 \pm 48.45^{* * *}$ & $134.17 \pm 22.74^{\#}$ & $108.33 \pm 15.19^{\# \#}$ & $98.75 \pm 17.05^{\#}$ \\
\hline $\mathrm{HDL}(\mathrm{mg} / \mathrm{dL})$ & $16.80 \pm 2.04$ & $9.83 \pm 1.30^{* *}$ & $8.50 \pm 1.46$ & $11.44 \pm 1.71$ & $12.25 \pm 2.88$ \\
\hline $\mathrm{TG}(\mathrm{mg} / \mathrm{dL})$ & $41.00 \pm 6.16$ & $34.60 \pm 3.29$ & $33.80 \pm 4.77$ & $38.71 \pm 6.35$ & $34.50 \pm 7.37$ \\
\hline Glucose (mg/dL) & $262.80 \pm 9.82$ & $418.67 \pm 26.47^{* *}$ & $245.67 \pm 14.54^{\# \#}$ & $215.33 \pm 10.23^{\# \# \#}$ & $371.25 \pm 40.82$ \\
\hline AST $(U / L)$ & $110.20 \pm 14.88$ & $175.17 \pm 28.16$ & $196.50 \pm 49.89$ & $162.67 \pm 31.01$ & $123.50 \pm 19.75$ \\
\hline $\mathrm{ALT}(\mathrm{U} / \mathrm{L})$ & $43.40 \pm 2.70$ & $100.67 \pm 27.88$ & $60.33 \pm 8.06$ & $46.78 \pm 2.43^{\#}$ & $49.25 \pm 4.50$ \\
\hline Creatinine (mg/dL) & $0.17 \pm 0.01$ & $0.18 \pm 0.01$ & $0.19 \pm 0.02$ & $0.13 \pm 0.02$ & $0.23 \pm 0.02$ \\
\hline
\end{tabular}

Abbreviations: Con, control; HFD, high-fat diet; T-chole, total cholesterol; $L D L$, low density lipoprotein; $H D L$, high density lipoprotein; TG, triglyceride; $A S T$, aspartate aminotransferase; $A L T$, alanine aminotransferase

All data represent mean values \pm SEM. $(n=8)$

${ }^{* *} P<0.01,{ }^{* * *} P<0.001$, versus chow diet fed $A p o E^{-1-}$ mice (control)

${ }^{\#} P<0.05,{ }^{\# \#} P<0.01$, and ${ }^{\# \# \#} P<0.001$, versus HFD-fed $A p o E^{-1-}$ mice (HFD) 
atherogenic plaque areas as compared to mice fed control diet $\left(3.20 \pm 1.69\right.$ vs. $\left.58.36 \pm 3.92 \times 10^{4} \mu \mathrm{m}^{2}\right)$. This increase was significantly antagonized by dose-dependent supplementation with Illicium $v$. $(23.69 \pm 3.32$ and $7.87 \pm$ $\left.2.89 \times 10^{4} \mu \mathrm{m}^{2}\right)$ or atorvastatin $\left(10.0 \pm 4.41 \times 10^{4} \mu \mathrm{m}^{2}, P<\right.$ 0.01 vs. HFD group) (Fig. 3a and b).

\section{Illicium $v$. attenuates iNOS expression in the aorta}

To explore action mechanisms of Illicium $v$. effects in hyperlipidemia with atherosclerosis, we studied aortic iNOS expression levels in the mouse model. Many iNOS cells were observed in the HFD-fed $A p o E^{-/-}$mice. Illicium v. $200 \mathrm{mg} / \mathrm{kg}$ treatment resulted in complete reduction of iNOS activation in HFD-fed $\mathrm{ApoE}^{-/-}$mice (Fig. 4a and b). Furthermore, iNOS expression was decreased by $200 \mathrm{mg} / \mathrm{kg}$ Illicium $\mathrm{v}$. in protein of aortic tissue (Fig. 4c). These data suggest an iNOS-dependent mechanism.

\section{Illicium v. inhibits production of inflammatory mediators} in the aorta

Previously published studies on sepsis show that high iNOS expression is associated with inflammatory mediators, such as TNF- $\alpha$, IL- $1 \beta$, NF- $k B$, and COX. These mediators also play an important role in the development and progression of atherosclerosis. We examined the effects of Illicium $v$. on expression of these proteins in aortic tissues. Levels of secreted TNF- $\alpha$, IL-1 $\beta$, NF- $\kappa B$, and COX proteins were significantly increased in aortic tissues from HFD-fed $A p o E^{-/-}$mice, and these increases were antagonized by supplementation with Illicium $v$. or atorvastatin $(P<0.05,<0.01$, and $<0.001$ vs. HFD group) (Fig. $5 \mathrm{a}$ and b). In addition, ІкB- $\alpha /$ Ікк- $\alpha / \beta$ expression was also increased in aortic tissue from HFD- fed $\mathrm{ApoE}^{-/-}$mice, and these increases were antagonized by Illicium $v$. or atorvastatin (Fig. 5c). These results suggest that Illicium $v$. regulates inflammatory gene expression via mediation of reduced iNOS activation.

\section{Illicium $v$. inhibits expression levels of adhesion molecules in the aorta}

To determine involvement of adhesion molecule expression, including ICAM-1, VCAM-1, and E-selectin, in the anti-inflammatory activities of Illicium $v$., protein levels were examined in western blots (Fig. 6a and b). Levels of ICAM-1, VCAM-1, and E-selectin were higher in aortas of untreated HFD-fed $A p o E^{-/-}$mice than normal controls. Treatment with Illicium $v$. or atorvastatin resulted predominantly in a dose-dependent downregulation of ICAM-1, VCAM-1, and E-selectin expression levels in aortas of HFD-fed $A p o E^{-/-}$mice. These results indicate that Illicium $v$. efficiently lowers adhesion molecule protein levels in hyperlipidemia-atherosclerosis.

\section{Discussion}

We have defined mechanisms involved in the beneficial effects of Illicium $v$. on atherosclerosis plaque lesions by investigating effects of the agent on anti-inflammatory responses in HASMCs in vitro, and in aortas of HFD-fed $A p o E^{-/-}$mice in vivo. We report that Illicium v. decreases characteristic changes in body weight, blood pressure, and lipid levels in HFD-fed ApoE-/- mice. In addition, Illicium $v$. strongly attenuates atherosclerotic plaque lesions in the aortas of those mice, and it decreases immunoreactivity of iNOS. Furthermore, significantly lower levels of TNF- $\alpha$, IL-1 $\beta$, NF- $\kappa B$, COX, IкB- $\alpha$, IKK- $\alpha / \beta$ and adhesion molecules were seen with Illicium $v$. treatment. The results clearly demonstrate beneficial

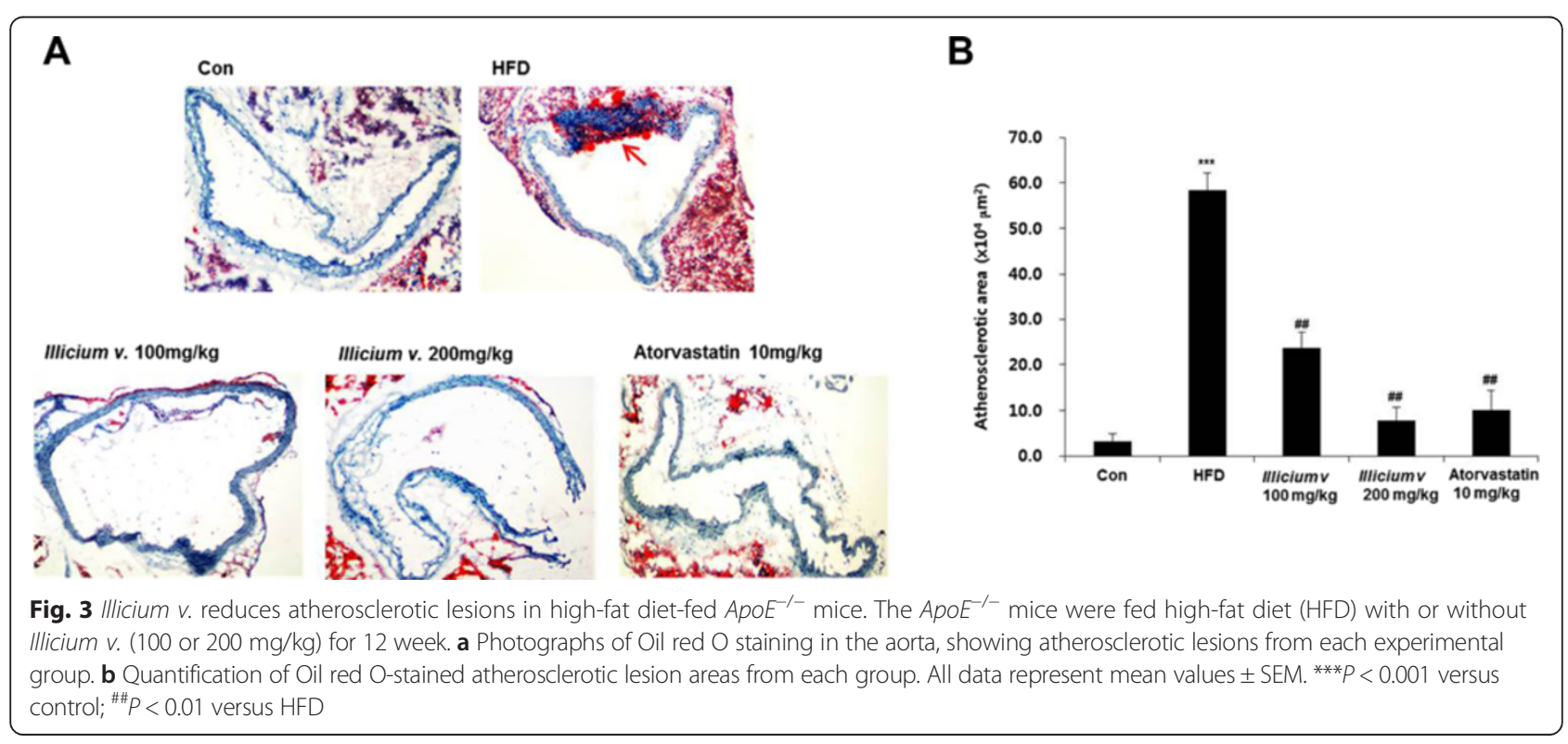




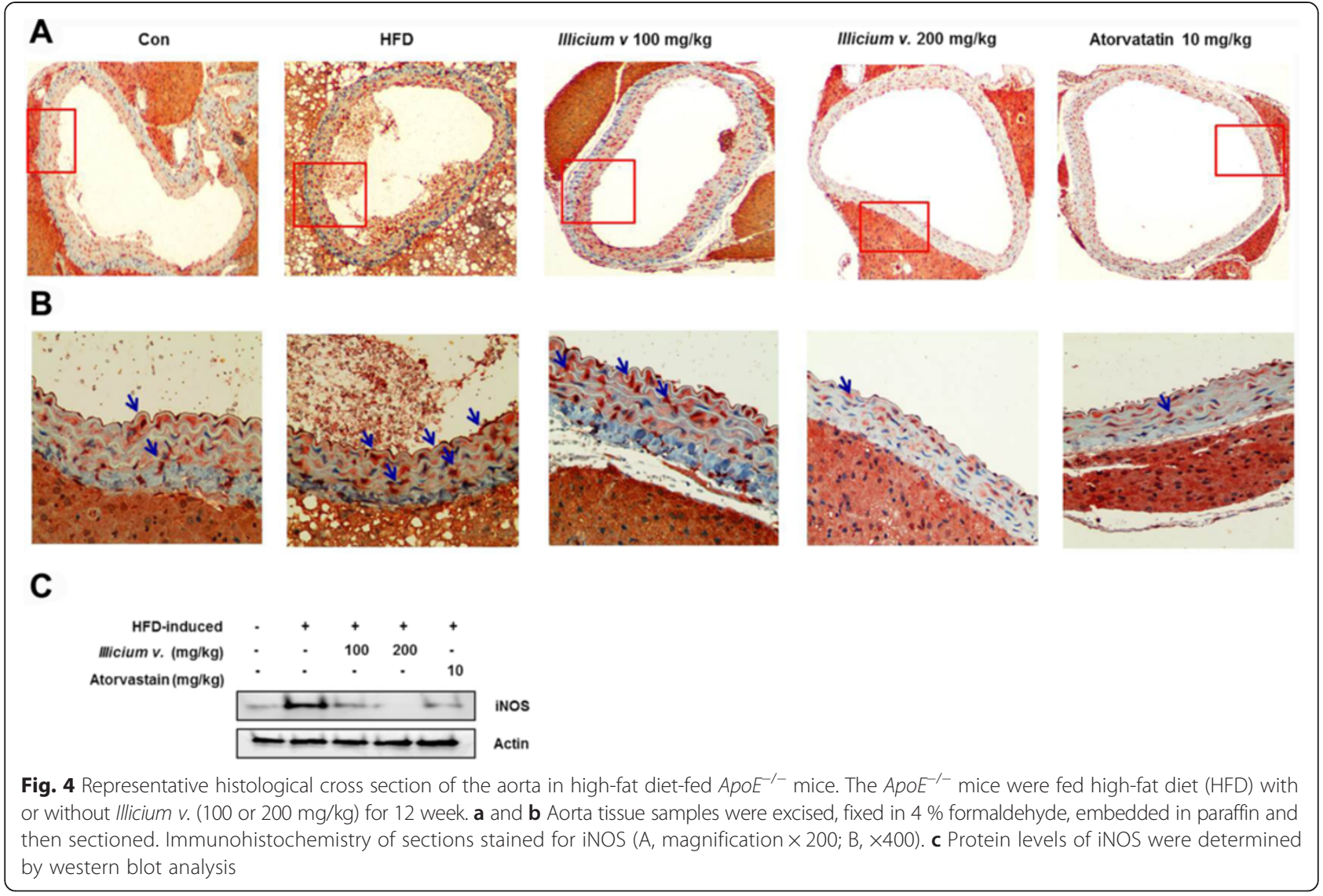

effects of Illicium $v$. on pathogenic atherosclerotic plaques and subsequent vascular impairment by vascular inflammation.

Pathogenesis of hyperlipidemia-atherosclerosis involves a chronic inflammatory state characterized by lipid deposition, accumulation of macrophages, and vascular smooth muscle cell proliferation in vascular walls $[24,29]$. These are all well-known events in the development of the disease. Additionally, anti-inflammatory compounds have been found to effectively inhibit atherosclerotic plaque formation in a hyperlipidemic animal model [22]. Therefore, an iNOS imbalance is regarded as an important cause for the development of inflammatory-related diseases. Abnormal activation of iNOS and enhanced levels of inflammatory proteins, such as NF- $\mathrm{kB}$, TNF- $\alpha$, and certain adhesion molecules, are observed in the coronary plaques of patients [8].

Overexpression of iNOS has a causal effect on the development of atherosclerosis. This has been previously established by showing that atherosclerotic lesions are attenuated when iNOS is knocked out in $A p o E^{-/-}$mice, creating the double knock-out strain. Elucidation of factors that modulate aggregation of atherosclerotic plaques and adhesion molecule expression is crucial for intervention in hyperlipidemia-atherosclerosis $[1,9]$. Several lines of evidence suggest that iNOS effects in vascular inflammation play a major role in hyperlipidemia pathogenesis, and they also influence various pathogenic processes implicated in hyperlipidemia [6]. Previous studies in hyperlipidemic murine models have demonstrated that lack of iNOS leads to a dramatic reduction in the size of atherosclerotic lesions. Furthermore, iNOS regulates expression of inflammatory cytokines, such as IL$1 \beta$, IKK- $\alpha / \beta$, and TNF- $\alpha$, in the aorta $[10,12]$. Therefore, modulating the function or levels of proteins involved with iNOS activity in the aorta will likely affect vascular inflammation and, ultimately, pathogenic processes in hyperlipidemia. In our study with HFD-fed $A p o E^{-/-}$ mice, Illicium $v$. was found to dramatically reduce the levels of inflammatory cytokines and adhesion molecules, subsequently improving atherosclerotic lesions. Moreover, Illicium v. reduced NF- $\mathrm{kB}$ expression. Therefore, the mechanism(s) of Illicium $v$. may reveal potential new targets for hyperlipidemia-atherosclerosis therapy, through its inhibitory activities against atherosclerotic lesion growth/aggregation and/or inflammatory responses. Moreover, Illicium v. decreased the activation of iNOS, which is responsible for inflammatory and atherogenic processes, in a dose-dependent manner in both HASMCs and in aortas of HFD-fed $A p o E^{-/-}$mice. Thus, results of 

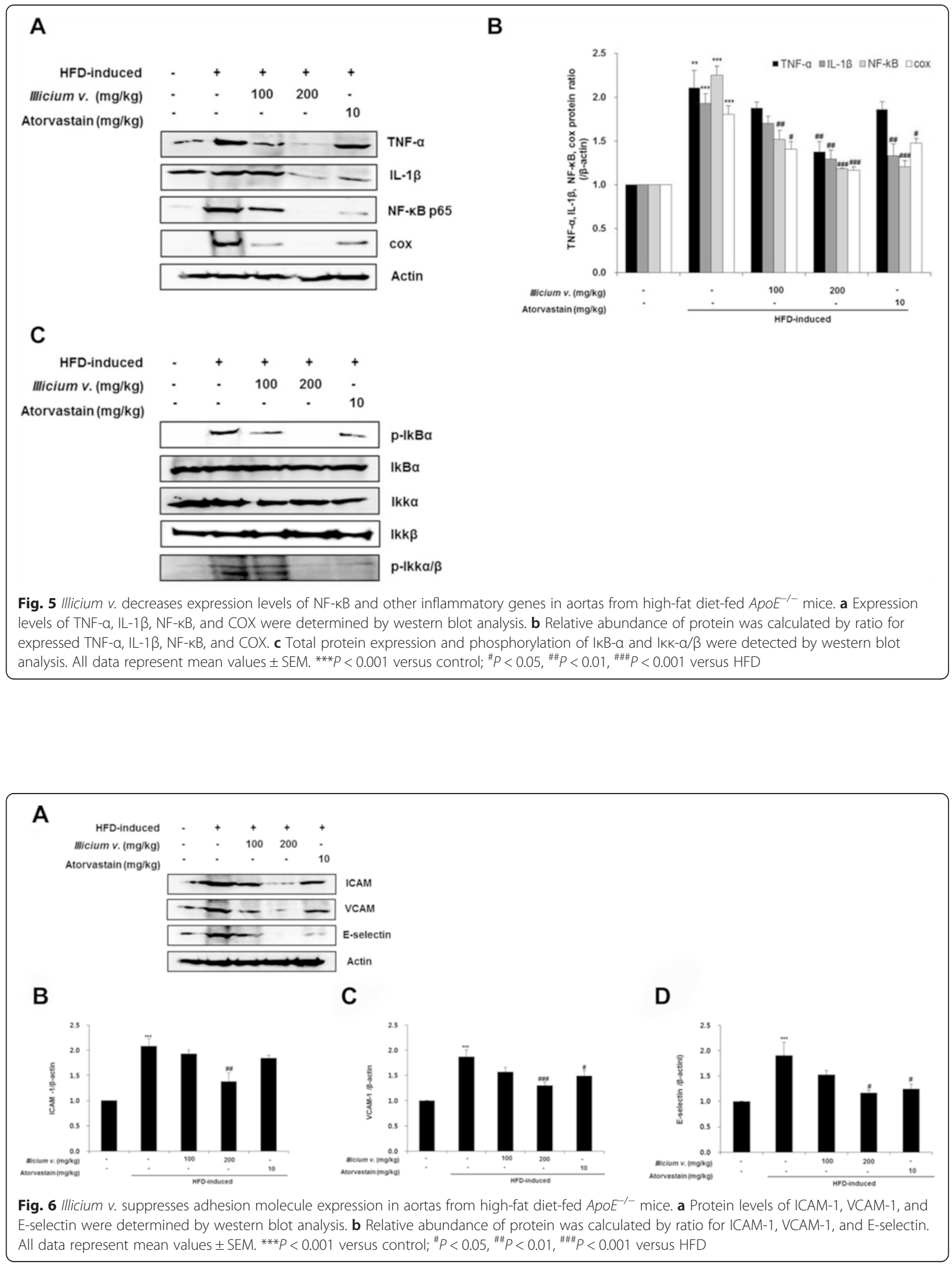
the present study suggest that beneficial effects of Illicium $v$. may be mediated through significant attenuation of the iNOS inflammatory response.

We recently reported that major chemical constituent of Illicium $v$. is trans-anethole [1-methoxy-4-(1-propenyl) benzene], which accounts for approximately 85$90 \%$ of the essential oil. Previous reports had indicated that ethanol extracts of Illicium v. contain high levels, approximately $2.14 \pm 0.01 \mathrm{mg} / \mathrm{g}$, of trans-anethole [28], and the anti-inflammatory and anti-oxidant effects of that compound occur through inhibition of lipid peroxidation [10]. In other studies, trans-anethole was found to decrease production of IL-1 $\beta$, IL- 6 , and TARC, to have anti-inflammatory properties in $\mathrm{HaCaT}$ cells, and to have anticarcinogenic properties through inhibition of TNF- $\alpha$-stimulated cellular responses $[5,30]$. Hence, trans-anethole may play a substantial role in the action of Illicium $v$. that we have described in our hyperlipidemia model.

We observed iNOS-positive immunostaining and elevated inflammatory cytokine expression, such as IL-1 $\beta$, IкK $\alpha / \beta$, and TNF- $\alpha$, in aortas of HFD-fed $A p o E^{-/-}$mice compared to controls, and these effects were practically abolished by Illicium v. treatment. Moreover, Illicium $v$. reduced expression of adhesion molecules. It has been reported that atherosclerotic lesion development is accompanied by upregulation of adhesion molecule levels. In hyperlipidemic aortas, inflammation is associated with atherosclerotic plaques in general $[19,21]$. Therefore, Illicium $v$. may be a potentially beneficial therapeutic drug that targets the inflammatory cascade critical for pathogenesis of hyperlipidemia-atherosclerosis.

In summary, we have demonstrated in HFD-fed $A p o E^{-1-}$ mice that Illicium $v$. suppresses aortic atherosclerotic lesion formation by antagonizing changes in body weight, lipid levels, levels of blood pressure, inflammatory cytokines, and adhesion molecules that are mediated through iNOS activation. Beneficial effects of Illicium $v$. may be explained by a significant reduction in the inflammatory response. Therefore, Illicium $v$. is a promising novel therapeutic drug for hyperlipidemiaatherosclerosis treatment.

\section{Conclusions}

We have described an Illicium v.-mediated attenuation of atherosclerotic lesion area (size of plaques) and iNOS activation. In addition, we found an inhibition of inflammatory cytokine and adhesion molecule expression, and subsequent blockade of the inflammatory response by the plant extract. These results indicate that Illicium $v$. may be a useful tool for developing new therapeutic opportunities for treatment of hyperlipidemiaatherosclerosis.

\section{Abbreviations}

HASMC: Human aortic smooth muscle cell; TNF-a: Tumor necrosis factor-a; ApoE: Apolipoprotein E; VCAM: Vascular cell adhesion molecule; ICAM: Intercellular adhesion molecule; NF-kB: Nuclear factor kappa B; KIOM: Korea Institute of Oriental Medicine.

\section{Competing interests}

The authors declare that they have no competing interests.

\section{Authors' contributions}

SHP, HKK participated in the design of the study. SHP carried out the experiments, analyzed the data, and wrote the manuscript. YYS and KJN carried out the animal study support. All authors read and approved the final manuscript.

\section{Acknowledgements}

This research was supported by the research program of the Korea Institute of Oriental Medicine (KIOM), South Korea (K15200). This research was also supported by the Bio \& Medical Technology Development Program of the National Research Foundation (NRF) funded by the Ministry of Science, ICT \& Future Planning, South Korea (NRF-2014M3A9D7034335).

Received: 31 March 2015 Accepted: 26 June 2015

Published online: 15 July 2015

\section{References}

1. Bai N, Kido T, Kavanagh TJ, Kaufman JD, Rosenfeld ME, Van Breemen C, et al. Exposure to diesel exhaust up-regulates iNOS expression in ApoE knockout mice. Toxicol Appl Pharmacol. 2011;255(2):184-92.

2. Brand K, Page S, Rogler G, Bartsch A, Brandl R, Knuechel R, et al. Activated transcription factor nuclear factor-kappa $B$ is present in the atherosclerotic lesion. J Clin Invest. 1996;97(7):1715-22.

3. Buttery LD, Springall DR, Chester AH, Evans TJ, Standfield EN, Parums DV, et al. Inducible nitric oxide synthase is present within human atherosclerotic lesions and promotes the formation and activity of peroxynitrite. Lab Invest. 1996;75(1):77-85

4. Cacicedo JM, Gauthier MS, Lebrasseur NK, Jasuja R, Ruderman NB, Ido Y. Acute exercise activates AMPK and eNOS in the mouse aorta. Am J Physiol Heart Circ Physiol. 2011;301(4):1255-65.

5. Chainy GB, Manna SK, Chaturvedi MM, Aggarwal BB. Anethole blocks both early and late cellular responses transduced by tumor necrosis factor: effect on NF-kappaB, AP-1, JNK, MAPKK and apoptosis. Oncogene. 2000;19(25):2943-50.

6. Chesebro BB, Blessing E, Kuo CC, Rosenfeld ME, Puolakkainen M, Campbell LA. Nitric oxide synthase plays a role in Chlamydia pneumoniae-induced atherosclerosis. Cardiovasc Res. 2003;60(1):170-4.

7. Chouksey D, Sharma P, Pawar RS. Biological activities and chemical constituents of Illicium verum hook fruits (Chinese star anise). Pelagia Res Library. 2010;1:1-10.

8. Depre C, Havaux X, Renkin J, Vanoverschelde JL, Wijns W. Expression of inducible nitric oxide synthase in human coronary atherosclerotic plaque. Cardiovasc Res. 1999;41(2):465-72.

9. Detmers PA, Hernandez M, Mudgett J, Hassing H, Burton C, Mundt S, et al. Deficiency in inducible nitric oxide synthase results in reduced atherosclerosis in apolipoprotein E-deficient mice. J Immunol. 2000;165(6):3430-5.

10. Freire RS, Morais SM, Catunda-Junior FE, Pinheiro DC. Synthesis and antioxidant, anti-inflammatory and gastroprotector activities of anethole and related compounds. Bioorg Med Chem. 2005;13(13):4353-435.

11. Huang Y, Zhao J, Zhou L, Wang J, Gong Y, Chen X, et al. Antifungal activity of the essential oil of Illicium verum fruit and its main component trans-anethole. Molecules. 2010;15(11):7558-69.

12. Kim CK, Cho DH, Lee KS, Lee DK, Park CW, Kim WG, Lee SJ, Ha KS, Goo Taeg O, Kwon YG, Kim YM :Ginseng Berry Extract prevents Athrosgenesis via Anti-Inflammatory Action by Upregulating Phasell Gene Expression. Evidence-Based Complementary and Alternative Medicine 2012: 1-14

13. Kim S, Kim CK, Lee KS, Kim JH, Hwang H, Jeoung D, et al. Aqueous extract of unripe Rubus coreanus fruit attenuates atherosclerosis by improving blood lipid profile and inhibiting NF-KB activation via phase II gene expression. J Ethnopharmacol. 2013;146(2):515-24. 
14. Kim JY, Kim SS, Oh TH, Baik JS, Song G, Lee NH, et al. Chemical composition, antioxidant, anti-elastase, and anti-inflammatory activities of Illicium anisatum essential oil. Acta Pharm. 2009;59(3):289-300.

15. Kuhlencordt PJ, Chen J, Han F, Astern J, Huang PL. Genetic deficiency of inducible nitric oxide synthase reduces atherosclerosis and lowers plasma lipid peroxides in apolipoprotein E-knockout mice. Circulation. 2001;103(25):3099-104.

16. Leal MA, Balarini CM, Dias AT, Porto ML, Gava AL, Pereira TM, et al. Mechanisms of enhanced vasoconstriction in the mouse model of atherosclerosis: the beneficial effects of sildenafil. Curr Pharm Biotechnol. 2015;16(6):517-30

17. Leuschner F, Panizzi P, Chico-Calero I, Lee WW, Ueno T, Cortez-Retamozo V, et al. Angiotensin-converting enzyme inhibition prevents the release of monocytes from their splenic reservoir in mice with myocardial infarction. Circ Res. 2010;107(11):1364-73.

18. Lin Q. Dissertation, College of Forestry. Guangzhou: South China Agricultural University; 1997

19. Liyama K, Hajra L, liyama M, Li H, DiChiara M, Medoff BD, et al. Patterns of vascular cell adhesion molecule-1 and intercellular adhesion molecule-1 expression in rabbit and mouse atherosclerotic lesions and at sites predisposed to lesion formation. Circ Res. 1999;85(2):199-207.

20. Matsui T, Ito C, Itoigawa M, Okada T, Furukawa H. Anti-inflammatory activity of phenylpropanoids and phytoguinoids from Illicium species in RBL-2He cells. Planta Med. 2007;73(7):662-5.

21. Nakashima Y, Raines EW, Plump AS, Breslow JL, Ross R. Upregulation of VCAM-1 and ICAM-1 at atherosclerosis-prone sites on the endothelium in the ApoE-deficient mouse. Arterioscler Thromb Vasc Biol. 1998;18(5):842-51.

22. Nam KW, Kim J, Hong JJ, Choi JH, Mar W, Cho MH, et al. Inhibition of cytokine-induced IkB kinase activation as a mechanism contributing to the anti-atherogenic activity of tilianin in hyperlipidemic mice. Atherosclerosis. 2005;180(1):27-35

23. Nathan C, Xie QW. Regulation of biosynthesis of nitric oxide. J Biol Chem. 1994:269(19):13725-8.

24. Ohsawa I, Nishimaki K, Yamagata K, Ishikawa M, Ohta S. Consumption of hydrogen water prevents atherosclerosis in apolipoprotein $\mathrm{E}$ knockout mice. Biochem Biophys Res Commun. 2008;377(4):1195-8.

25. Shoufen L, Shaohua L. Chemical constituents of essential oil from Cenxi's Illicium. China Condiment. 2000;20:69-70.

26. Siasos G, Tousoulis D, Oikonomou E, Zaromitidou M, Stefanadis C, Papavassiliou AG. Inflammatory markers in hyperlipidemia: from experimental models to clinical practice. Curr Pharm Des. 2011;17(37):4132-6.

27. Sung YY, Kim YS, Kim HK. Illicium verum extract inhibits TNF-a and IFN-g induced expression of chemokines and cytokines in human Kerationocytes. J Ethnopharmacol. 2012;144(1):182-9.

28. Sung YY, Yang WK, Lee AY, Kim DS, Nho KJ, Kim YS, et al. Topical application of an ethanol extract prepared from Illicium verum suppresses atopic dermatitis in NC/Nga mice. J Ethnopharmacol. 2012;144(1):151-9.

29. Usui F, Shirasuna K, Kimura H, Tatsumi K, Kawashima A, Karasawa T, et al. Critical role of caspase-1 in vascular inflammation and development of atherosclerosis in Western diet-fed apolipoprotein E-deficient mice. Biochem Biophys Res Commun. 2012;425(2):162-8.

30. Wang GW, Hu WT, Huang BK, Qin LP. Illicium verum: a review on its botany, traditional use, chemistry and pharmacology. J Ethnopharmacol. 2011;136(1):10-20

31. Wilcox JN, Subramanian RR, Sundell CL, Tracey WR, Pollock JS, Harrison DG, et al. Expression of multiple isoforms of nitric oxide synthase in normal and atherosclerotic vessels. Arterioscler Thromb Vasc Biol. 1997:17(11):2479-88.

\section{Submit your next manuscript to BioMed Central and take full advantage of:}

- Convenient online submission

- Thorough peer review

- No space constraints or color figure charges

- Immediate publication on acceptance

- Inclusion in PubMed, CAS, Scopus and Google Scholar

- Research which is freely available for redistribution

Submit your manuscript at www.biomedcentral.com/submit 